\title{
Sustainable Language and Literacy Learning: A Critical Trace in English Language Education
}

\author{
Khadijeh Aghaei (Corresponding author) \\ $\mathrm{PhD}$, Universiti Kebangsaan Malaysia \\ School of Language Studies \& Linguistics, Faculty of Social Sciences and Humanities \\ 43600 UKM Bangi, Selangor, Malaysia \\ Tel: 60-173-269-841 E-mail: aghaee55@yahoo.com
}

Koo Yew Lie

Professor. Dr., Universiti Kebangsaan Malaysia

School of Language Studies \& Linguistics, Faculty of Social Sciences and Humanities

43600 UKM Bangi, Selangor, Malaysia

Tel: 60-122-067-216Ｅ-mail:kooyewli@gmail.com

\author{
Noorizah Mohd Noor \\ Dr., Universiti Kebangsaan Malaysia
}

School of Language Studies \& Linguistics, Faculty of Social Sciences and Humanities

43600 UKM Bangi, Selangor, Malaysia

Tel: 60-193-071-619Ｅ-mail: izah@ukm.my

Received: February 15, 2012

Accepted: March 6, 2012

Published: June 1, 2012

doi:10.5539/elt.v5n6p54

URL: http://dx.doi.org/10.5539/elt.v5n6p54

\begin{abstract}
In recent years, interdisciplinary studies have become one of the most inspiring and productive of human pursuits so that it can provide a format for connections and conversations giving rise to new knowledge. Such a wedding interest has also been gleaned in issues of English in Education from New literacy perspective and emerged an overgrowing field named English language and literacy education. However, understanding of what constitutes English literacy and who is a literate person in English in the 21 century has become a complex puzzle. A paucity of an integrated pattern or more plausible definition of literacy has brought about many challenging approaches to those working in the newly- made field. Scrutinizing most approaches which have so far posed can bring them under the wing of two different views i.e. cognitive and sociocultural approaches to the language and literacy education. This explanatory study is to take into account some of the main heeds of these two general approaches. Such a task can provide a more integrated definitional pattern for all those who are in the front. It can also act as a conceptual construct for curriculum developer, teachers and all educational practitioners to move consciously in achieving a more durable learning and teaching in the educational terrain.
\end{abstract}

Keywords: Sociocultural approach, Cognitive approach, Literacy practices, Sustainable literacy learning

\section{Introduction}

English language education from new literacy perspectives has recently become an increasingly important era. (Koo et al., 2006) Recent developments in the newly made interdisciplinary field have led to new challenges as well. Despite its ever-increasing growth, this new field still suffers from a major drawback i.e. lack of an integrated definitional pattern for all those who are in the front. This issue i.e. what constitutes English literacy learning and who is a literate person in English in the 21 century has become a complex puzzle and a buzzword. The controversy about a more cohesive meaning has raged unabated for over two decades. Reviewing the most dominant works done in this field can categorize them in two general wings i.e. cognitive and sociocultural view to English language and 
literacy learning. In addition to listing the main heeds of these two views, the objectives of this research which is a critical explanatory study are to determine which one can move toward a more sustained and durable learning.

\section{Concept of Sustainable Language \& Literacy Learning}

Comparing the most dominant works in language education from literacy perspective i.e. the two different approaches namely cognitive, currently advocated approach, versus socio-cultural, recently oriented approach can be giving rise to the following questions:

\subsection{Is Language and Literacy Learning Objective- Based or Subjective- Based?}

In cognitive views, language literacy practices as merely observable units of behavior or a set of features or properties reside in individuals are understood. In this school of thought, Practices are concrete concepts of common or typical activities or tasks. Whereas, the concept of practices include a much more fundamental link between activities comprised reading and writing and imbedded social, cultural structures in them. Such an attitude has been floated in social theory of literacy where literacy practices, main units of study, can be defined as cultural ways to use language which people are dealing with in their lives. To put it simply, literacy practices are "what people do with literacy". In fact, what should not be ignored is that practices can be unobservable or subjective behavioral units consisting of values, attitudes, feelings and social relationships. Further, some literacy practices will be more under the effect of some power relationships or hierarchies and social norms and consequently will be more dominant and crystallized compared to others. As a result, to obtain mastery and learning some literacy practices will be more centered in every particular context. In this climate, in other words, we witness the growth of some literacy practices than others (Street, 1993; Barton et.al, 2000; Koo et.al, 2006).

These social views to literacy can take into consideration two categories namely internal processes to individual which includes people's awareness of literacy, literacy constructions, literacy discourses and the way people are making meaning of literacy being focal point of cognitive approaches, specifically, humanistic approach and also simultaneously the second category i.e. Social processes linking different people with each other, and they are internalized in ideologies, social and cultural identities of people living in every specific context. The latter is exactly what has been ignored by cognitive approaches. (Barton et.al, 2000). What should be emphasized here, however, is that these two categories are both collected in sociocultural approaches. Therefore, in order to find out the distinguishing points between individual and social worlds, literacy practices which are existing in the relationship among people, within groups and societies instead of a specific set of features embedded in individuals must be examined more and more. It is worth noting that the usage of practices should be considered to be fully different from that of schools of thought in which the word practice is seen as learning something through repetition or the common, conventional definition existing in cognitive theories as observable activities or tasks. The above mentioned definition of literacy practices- cultural ways of literacy usage- is a much more abstract or subjective concept which cannot be fully achieved in observable and tangible activities and tasks. (ibid)

\subsection{Is Language and Literacy Learning a Set of Procedures Focusing on Product or Process?}

Many scholars as Fathman et al. (1992), Thomas et al. (2000) implied language is a set of procedures in which product not process is the main concern. This point of view is one currently advocated view point welcome by many pioneers in cognitive approaches so that language literacy in general and literacy in specific is defined as technically developing a set of isolated and basic cognitive skills which can be tested and measured and varied from one context to another. Degree of success is majored through individuals' capability in achieving a plausible considered level of literacy standards. From such aspect, those who cannot achieve determined standards are labeled and identified as illiterate. This view of literacy is termed as autonomous model of literacy (Street, 1995, 2003 cited in Azman, 2006). Such a framework which is so much adhered to in diverse educational institutions (Pennycook, 2010) can be practically illustrated in the following description posed by Nesbit and Shucksmith (1991) of a typical child called Bill who is stated in such a system:

"Bill is one of life's plodders, (un) consciously looking for and sticking to the one right method of working. It is a strategy which, unfortunately, pays off in many school situations, and he will probably end up with a reasonably good set of grades and a school report which describe him as a good student. His inability to adapt to changing requirements and his lack of self-knowledge may start to be a problem when he is expected to study on his own. But for the present, his teacher do not see him as a problem and are quite glad to have a few like Bill in their classes"( quoted in Williams \& Burden, 1998: 147-8).

As depicted above, a learner like Bill who is the product of cognitive approach can at best obtain good scores in separated skills based on standard defined which are free from the notions of social, cultural, historical contexts which may have a great impact on his literacy learning and practices. Koo \& Kell (2006: 3) also contends that such 
views of literacy are decontextualized and, as a consequence of these narrow perspective, literacy his taken into consideration at "the hands of the individual and/or her community and where there is illiteracy, the blame rests on the individual or her community".

In addition, in such approaches, "passing of information" to learners (Winters, 2004) or quantity or amount of information transmitted is of importance. In fact, simply put it, learning is quantity-based not quality-based. There is an over emphasis on the textbooks aiming that transmitting information included in them to the learners. The more input you obtain, the best output will be achieved and consequently the more professional you will be is one slogan which are even reflected in planning current curricula i.e. Proficiency and accuracy as the ultimate goal of language learning can be merely obtained through such a dominant quantity-based lens of these approaches.

What lacks in cognitive approaches or autonomous models of literacy which are product-oriented to teaching language, is a view of education not going beyond language proficiency. However, literacy practices can be viewed from a broader and more inclusive perspective named "ideological approach" to literacy (Street, 1998, 2003) that looking beyond a mere functional instrumental view, concentrating on post-cognitive, social, cultural, and ideological issues. Social practices, in other words, dependent on context, power relations, and culture of people from which they originated. A Socio-cultural perspective on language and literacy takes language into consideration as a tool for meaning portraying identities, achieving social/cultural goals. They put much more emphasis on process and practices in meaningful activities, not on the cognitive capacities (Street 2003; Barton et.al, 2000).

In line with Street, Koo (2005) states that language and literacy are widely accepted to be situated, "pluralistic" and various in meaning- making in which practices are closely associated with "situated meanings, texts, languages, popular /everyday culture,......and vernacular knowledge from primary and secondary life world" instead of being merely adhered to the view that language proficiency does matter and literacy is viewed as "singular, discrete and monolithic" (cited in Koo et.al, 2006: 2).

\subsection{Is Language Literacy Learning a Static or Dynamic Process?}

Turning to another basic concept in cognitive perspectives, Literacy practices are analysis units which are of a much more fixed, less flexible nature .In other words, they seem to be more static than to be dynamic. The root of such a school of thought is hidden in the putting much more emphasis and giving much centrality to the language merely in the meaning making and knowledge production belonging to participants in literacy events. Their justification , according to Koo (2006), to postulate the language centrality is that language as a system is of a much closed and integrated nature, so this close- ended view to language will make it deprived of enjoying any major shift and dedicate to the knowledge and consequently literacy practices in this trend a less flexible or more static nature.

However, the other school of thought i.e. sociocultural approach holds the view that language alone is not sufficient in any contemporary view to literacy. Language is considered to be a communication channel aimed at communicating social reality embedding the participants "sociocultural beliefs, values and norms in the contexts. Applying specific linguistic codes are of meaning since they portray specific institutional, social norms, relationships, institutions, practices and ideologies. Individuals as a body of different communities and also communities by themselves are enjoying at the same time, multiple, overlapping and distinctive social and linguistics worlds (ibid). It goes without saying that modality and shifts from a context to another context and from time to time is viewed as an inherent part of every society and its chains namely its individuals, therefore such changes and modalities will be reflected in practices so that they will be changeable. As Barton et.al. (2000) state, Literacy practices change and new ones are frequently acquired through processes of informal learning and sense making.

\subsection{Is Language Literacy Learning a One -Way or Two- Way Instruction?}

In literacy education or even foreign/second language educational settings, student's participation has been centered as one of the main indicator in academic performance (Halliday, 1978). One of dominant features of majority of cognitive classrooms is its over emphasizing on knowledge or literacy transferability, which mainly the direction of such a transferring is from teacher to the students or so-called teacher-directed or among students which takes a name of one-way instruction. Such a linear orientation to knowledge or literacy learning practices allocates and gives rise to considering a minimum space to all learners 'orientation (Abednia, 2008). Freire (1972), In his most seminal work, Pedagogy of the Oppressed has also contended that education, as currently presented and practiced, is mainly based on a banking framework in which learners are mainly passive recipients of deposits of pre-selected and pre-packaged knowledge. A tangible drawback of such a transmission-based type of education is nothing but marginalization of some learners which at worst leads to suffocation of critical consciousness on the part of learners who won't be able to rethink their original reading of the world around them (Freire, 2005). He makes the picture much more tangible through focusing on the banking approach in adult education as follows: 
"The banking approach to adult education, for example, will never propose to students that they consider reality critically. It will deal instead with such vital questions as whether Roger gave green grass to the goat, and insist upon the importance of learning that, on the contrary, Roger gave green grass to the rabbit". (Freire, 1972: 48)

In this kind of context, teachers are required to transfer the prespecified content to learners in a prescribed fashion and both learners and teachers are frowned upon if they question the legitimacy of either content or methodology (Moreno-Lopez, 2005; Kumaravadivelu, 2006; Freire, 1972). However, this concept that literacy learning is situated in community of practices (Lave \&Wenger, 1991; Wenger et. al, 2002; Bartoon \& Hamilton, 1998) can put an end to absolute truthiness of knowledge transferred putting under question power relations dominant on the context. In situated literacy learning students are viewed as apprentices situated in whom they are "active participants in the practices of social communities" (Wenger, 1998: 4). As Wenger (1998) mentioned, participation is result of juxtaposition of two concepts, namely, action or process of taking part \& connection or the relations with others that reflect this process. Such a point of view can be also interpreted as negotiating or dialoguing of knowledge or literacy practices which firstly coined by Freire (1972). This negotiation of knowledge in some works associated with sociocultural approaches has also been labeled as cooperative or collaborative literacy learning which essentially includes students learning from each other in groups where merely group configuration is not an indicator for the name of collaborative but as mentioned earlier, the way or negotiation through which learners \& teachers is experiencing a challenging and unique learning made it more different and durable (Larsen-Freeman, 2000).

All in all , according to Johnson (1994: 4) this kind of learning can be described as a process where learners through making a cooperative / negotiating group seeking offshoots beneficial to themselves or other members of group so that it can lead to maximize their own and each other's learning which can be contrasted with the competitive literacy learning floating in cognitive approaches in which learners make a competitive one -way context where one ultimate goal is to obtain such a grade as A. Yet, due to a number of the fore mentioned limitations from cognitive approaches, literacy learning as an objective, static, quantity-based, and one-way process, socio-cultural approaches have highlighted the contributory role in language and literacy learning. Such (an) approach(es) also put(s) a finger on the impact of many environmental factors which are mainly social/cultural interaction on learning process. Jaworski (1996) believes that learning is integration into a community of practice and discourse prevalent among affiliates of a learning community (Pourdavood et.al, 2005). He added that children come into this social existence and their learning is the fruit of social interaction happening between themselves and those who mediate learning process (Williams \& Burden, 1998). So, including social and cultural background of the students in the classroom literacy practices should be considered as a prerequisite to teaching and learning literacy. Indeed, such factors as ethnicity, gender, socioeconomic and sociopolitical status, religion, just to name a few, which are internalized in social and cultural context can be termed as a sociocultural perspective. In a more narrowed sense, a socio-cultural perspective is seeking to better comprehend student's literacy learning in their social and cultural context rather than taking literacy learning is to consideration as mere transmitting and internalizing a bulk of universal cognitive skills. (Kim, 2001; Street, 1998; Bartoon \& Hamilton, 2003)

\section{Concluding Remarks}

Considering the above mentioned arguments, It can be concluded that, here, language literacy learning can be defined as sustainable when it is a two-way or negotiable, dynamic, quality-based process which socially, culturally constructed between learners and learner -mediators. Comparing the two older \& new concepts of literacy learning , making a shift from cognitive to socio-cultural in various subfields of language and literacy education, although it happened in prior in many areas, to achieve a sustainable language literacy learning seems to be necessary. This paper models an appropriate frame (Figure 1) from the above mentioned features aimed at giving a much more comprehensive definition of Sustainable Language Literacy Learning (SLLL). This model can be considered as a building block for many theories of English language and literacy education by those concerned to give more achievements in this profession.

\section{References}

Abednia, A. (2008). A Social Constructivist Approach to Academic materials Development. Iran: Samt Press.

Barton, D., Hamilton, M., \& Ivanic, R. (2000). Situated literacies: Reading and writing in context. London \& New York: Routledge.

Barton, D., \& Hamilton, M. (2003). Local Literacies: Reading and Writing in one Community. London: Routledge.

Fathman, A. K., Quinn, M. E., \& Kasseler, C. (1992). Teaching Science to English Learners. Washington, DC: Office of Bilingual Education and Minority Languages Affairs. 
Freire, P. (1972). Pedagogy of the oppressed. New York: Penguin Books.

Freire, P. (2005). Teachers as cultural workers. United States: Westview Press.

Halliday, M. A. K. (1978). Language as Social Semiotic. London: Edward.

Hazita, A. (2006). English language in rural Malaysia: Situating Global Literacies in Local Practices. Journal of Language teaching, Linguistics and literature, 6.

Jaworski, B. (1996). Constructivism and Teaching the Socio-cultural Context. [Online] available: http://www.grout.demon .co.uk/ Barbara/ chreods.htm

Kim, B. (2001). Social constructivism. In M.Orey (Ed), Emerging perspectives on learning, teaching and technology. [Online] Available: http:// www.coe.uga.edu/ epltt/social constructivism.htm

Koo, Y. L., Kell, P., \& Wong F. F. (2006a). Language, Literacy and Diversity @ 21 century: A New Basic for Designing Global Learning. 3L Journal of Language Teaching, Linguistics and Literature, 12. 1-12. School of Language studies and Linguistics, UKM. (International).

Koo, Y. L., \& Kell, P. (2006b). Language, Literacy and Education in Diverse Contexts: Theory, Research and Practice. 3 L Journal of Language Teaching, Linguistics and Literature, 11, 1-14. School of Language studies and Linguistics, UKM. (International).

Koo, Y, L. (2006c). Exploring Pluriliteracy as Theory and Practice in Multilingual/ Cultural Context. 3 L Journal of Language Teaching, Linguistics and Literature, 11, 79-98. School of Language studies and Linguistics, UKM. (International).

Kumaravadivelu, B. (2006). Understanding language teaching: From method to post method. Mahwah: New Jersey. Larsen -Freeman, D. (2000). Techniques and Principles in Language Teaching. Second Edition, Oxford University Press.

Lave, J., \& Wenger, E. (1991). Situated learning: Legitimate Peripheral Participation. Cambridge: Cambridge University Press.

Moreno-Lopez, I. (2005). Sharing Power with Students: The Critical Language Classroom. Radical Pedagogy, CAAP.

Pennycock, A. (2010). Critical Applied Linguistics: A critical introduction. Lawrence Erlbaum Associates, Inc.

PourDavood R., Svee L. V, \& Cowen L. M. (2005). Social constructivism in practice: case study of an Elementary school's mathematics program. Focus on Learning Problems in Mathematics, Winter_Spring.

Street, B. (ed). (1993). Cross- Cultural Approaches to Literacy. Cambridge: Cambridge University Press.

Street, B. (2003). Literacy and development: Ethnographic Perspective. Routledge: London \& New York.

Thomas, A., O'Donoghue., \& Ron Chalmers. (2000). How teachers manage their work in inclusive classroom. Teaching and Teacher Education, 16(8), 889- 904. http://dx.doi.org/10.1016/S0742-051X (00)00033-0

Wenger, E. (1998). Communities of Practice: Learning, Meaning and Identity. Cambridge: Cambridge University Press.

Williams, M., \& Burden R. L. (1998). Psychology for language teachers: A social Constructivist approach. Cambridge: Cambridge University Press.

Winter, E. (2004). Shapes Shifting. [Online] Available: http://www.ewinters.com/shapeshift 1.html.Elaine Winters 


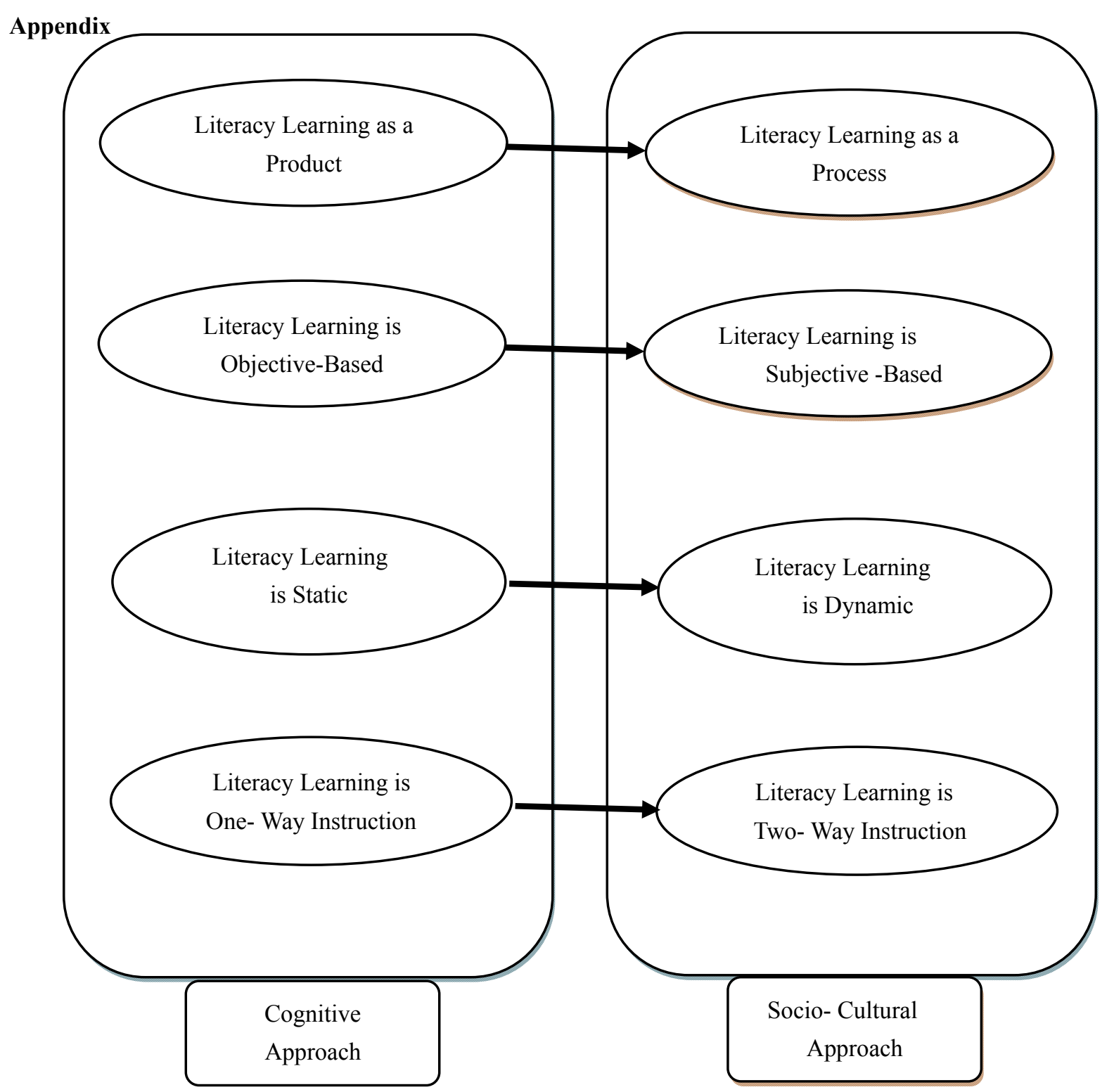

Figure 1. A Sustainable Language \& Literacy Learning Model (SLLL Model) 